\title{
Sound as Material for Eco-technogenesis
}

\author{
Megan Hines \\ Department of Art \\ Stony Brook University \\ 2224 Staller Center for the Arts \\ Stony Brook, NY 11794 \\ United States \\ megan.hines@stonybrook.edu
}

\author{
David Kadish \\ Robotics, Evolution, and Art Lab \\ IT University of Copenhagen \\ Rued Langgaards Vej 7 \\ DK-2300 Copenhagen S \\ Denmark \\ davk@itu.dk
}

\author{
Maja Fagerberg Ranten \\ Department of People and \\ Technology \\ Roskilde University \\ Universitetsvej 1, 10.2, \\ DK-4000 Roskilde \\ Denmark \\ mranten@ruc.dk
}

\begin{abstract}
This paper delineates the conceptual outcomes from a two-week intensive cross-disciplinary conversation between an art historian, an interaction designer, and an artist/engineer. With the aim of applying the concept of technogenesis to an exploration of sound as material for art and design, we consider sound as a material force within an ecosystem. Through this lens, sound produced by either life- or technological-forms allows us to consider the ecological impact and potential meanings of generated sound. Drawing on biosemiotics, we propose that the co-evolution of sound, technology, and environments, what we call eco-technogenesis, demands relational, and thus ethical, thinking. The rowdy krause, an autonomous sonic agent, designed by Kadish to identify and inhabit an acoustic niche within an ecosystem, serves as a case study for thinking through ecotechnogenesis.
\end{abstract}

Biosemiotics. Ethics. Soundscape ecology. Sound objects. Technogenesis.

\section{INTRODUCTION}

This article is the conceptual outcome of a two-week intensive research- and practice-based collaboration between Megan Hines, an art historian, Maja Fagerberg Ranten, an interaction designer, and David Kadish, an artist/engineer. Drawing on conversations that took place at Catch: Center for Art, Design, and Technology, Helsingør, and the RE:SOUND Conference, Aalborg, we discuss sound as a material and the ecological impact and potential meanings of generated sound. Approaching our topic from a cross-disciplinary lens, we posit that the increasing presence of generated sound within ecosystems demands expanding technogenesis to the non-human realm. We propose bio- and eco-technogenesis as tools to consider the relationality of generated sound.

Technogenesis, as developed by Bernard Stiegler (1998) and expanded on by Katherine Hayles (2012) describes human evolution as occurring as a result of interactions with the environment and the available tools or technologies within that environment. Technogenesis is a co-constituted process of becoming, an intertwining of the past, present, and future trajectories of the techno-human ensemble. In this framework, technologies drive shifts in human genetic, epigenetic, and developmental traits. Though the process is nonteleological, the entities as they currently exist could not have existed independently and are rendered meaningless without one another. Stiegler (1998) traces a line from the emergence of bipedal mobility and the freeing of the hands to the beginnings of tool use and the development of a co-constitutive relationship between technics and human genetic and epigenetic changes. He argues,

"the prosthesis is not a mere extension of the human body; it is the constitution of this body qua 'human"' (1998, p. 152).

Hayles (2012) focuses on contemporary technogenesis, aiming to describe the unprecedented change and amplified feedback loops that digital technologies have activated in our environment and ourselves.

We argue here that this process of technological becoming can and should be applied to other biological forms as well as to ecosystems. The inherently relational quality of sound provides an excellent medium through which to introduce ecological thinking to the concept of technogenesis. Soundscape ecology, sometimes called ecoacoustics or soundscape studies, is the study of sounds in an ecosystem. Its history predates its naming. For example, ornithologists tookadvantage 
of sound recording technologies as soon as it was plausible to bring them into the field in the late nineteenth century. These studies concentrated on single bird songs in order to preserve and analyse them. Soundscape ecology incorporates individual sounds into a whole soundscape, a term coined by Canadian composer R. Murray Schaffer (1969). Schaffer's concept of a soundscape was groundbreaking for including sounds made by humans, nature, and machinery, whether electric or mechanical (Ibid., 5-6). The soundscape was a landmark contribution to soundscape ecology because it moved the study of sonic relations beyond the confines of music. Furthermore, the soundscape pushed the study of sound into a wider realm that included non-human and non-organic listeners and creators. To accept that sound acts as an ecological force implies that its effects go beyond human aesthetics and touch on material relations within an environment.

\subsection{Cross-disciplinary Backdrop}

The topics of technogenesis and soundscape ecology are necessarily cross-disciplinary, spanning fields as wide as sound studies, ecology, evolutionary biology, anthropology, and media studies. As representatives from three different fields of study, we spent two weeks together in Denmark in August 2019: the first week as participants at the workshop Artistic and Curatorial Practices in the Age of Technogenesis at Catch in Helsingør; and the second week at the 2019 Media Art Histories conference in Aalborg titled RE:SOUND Sound, Media and Art - Theories, Histories, Practices.

Throughout the two weeks, we discussed what is at play when we consider sound as material within an ecological soundscape. How do we define and perceive sound? How do nonhumans perceive sound? Moreover, what happens when one perceives sound that is computationally generated? By acknowledging that sound acts as an ecological force, we discuss the effects of sound beyond human aesthetics within an ecosystem.

The work-in-progress explored at the preconference workshop, Kadish's the rowdy krause, serves as a subject for our conversation. We begin our discussions through the presentation of three conversation themes, followed by a conversation between us based on our respective practices. We posit that viewing technogenesis from a crossdisciplinary lens can broaden the perspective on sound as material within ecological soundscapes. The two conversation themes are sound as computational material and eco-technogenesis.

\subsection{The Rowdy Krause}

The rowdy krause is an autonomous sonic agent that is designed to inhabit an ecosystem and find an acoustic niche for itself within that ecosystem's soundscape. The work is currently in progress (see Figure 1), but the rowdy krause is already able to perform its search for a niche using a recorded soundscape, while future iterations will perform this in real-time, embedded in an ecosystem.

The rowdy krause begins its search for a niche by listening to the soundscape in which it is placed. It makes note of the different sounds that it hears and analyses their spectra so that it can start to determine which frequencies are least used. It continues listening and revising its understanding of what already exists in the soundscape throughout the process of evolving its own voice.

To make sound, the rowdy krause makes use of a computational model of a mammalian vocal tract so that the sounds that it produces have something in common with sounds that one might hear from a biological creature. The simulator was developed by Neil Thapen and is called Pink Trombone. ${ }^{1}$ The rowdy krause controls the simulator using an evolutionary neural network that uses a process called the neuroevolution of augmenting topologies (NEAT), meaning that the structure and weighting of the neural network both undergo evolution (Stanley, 2002).

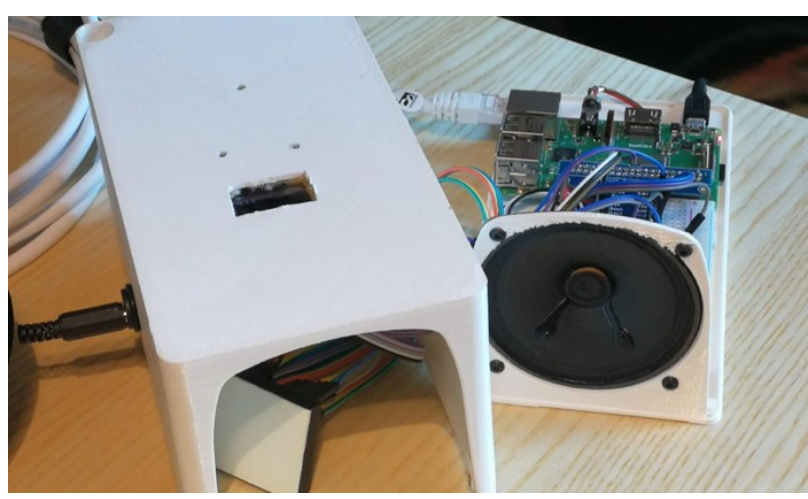

Figure 1: The rowdy krause's physical instantiation in progress. The rowdy krause's computation occurs on a Raspberry Pi single board computer, and it senses its surroundings using a microphone, temperature and humidity sensor, and light detector, while engaging with the world through an amplified speaker.

Every time the neural network produces a vocalization by controlling the vocal tract, the vocalization is compared to all of the sounds that the rowdy krause has already heard in the ecosystem's soundscape. The neural network is assigned a fitness based on how different the sound it produces is from the existing soundscape and the networks with the best fitness are more likely to pass on traits to the next generation of neural networks in the evolutionary process. Over time, the rowdy krause tends toward finding a voice that occupies a unique niche within its soundscape. 
While the parameters for the rowdy krause's voice are selected by Kadish, the actual voice arises from the particular composition of the ecosystem that it inhabits. At the same time, the projection of the evolving vocalizations into the ecosystem adds to the soundscape and affects other ecosystem inhabitants. Their responses and the new voice are part of the ecosystem's continual evolution, and also drive the evolution of the rowdy krause's vocalization, an example of eco-technogenesis in action.

\section{SOUND AS COMPUTATIONAL MATERIAL}

Sound made by humans and machinery ranges from recordings, digitized sounds and algorithmicallygenerated sounds. Typically, humans author content; the composer, artist, designer, or developer uses sound as material in their technologically-aided practice. The idea of sound as immaterial or ephemeral has changed as the technological possibilities for the recording and manipulation and sound increased. Composer Pierre Schaeffer was the first to refer to an "object sonore" or sound object (Schaeffer, 1966). As audio technologies progressed, recorded sound objects no longer referred to a sound source, but existed as objects in their own right (Chattopadhyay, 2017).

Joseph Klett has extended the materiality of sound to the sonic object setting, the place of interaction between material sounds and their interpreters (Klett, 2014). Besides labelling sound as social as it occurs among bodies, Labelle (2006) addresses sound as spatial. Sound is always more than one place and performs with and through space. Sound is a relational phenomenon: from immaterial to material, from inside one's thoughts to others', and through space (Labelle, 2016, p. xi).

Søndergaard (2019) describes sound as the perfect material for experimental practices because of its "difficulty" as time-based, immaterial and fugitive. He adds that sound is nothing without being experienced. He describes sound as an artist's material and the first media art practice:

\footnotetext{
"...and because of the invention of technologies that make it possible to liberate sound from its source, sound even became the first technologically emerging artistic material; as such, sound art could be seen as the first media art practice, historically." (Søndergaard, 2019, p. 96).
}

Cox (2013) elaborates on sound having a sonic ontology. He states that whereas the ontology of "matter" privileges sight and touch, the invisible, intangible and ephemeral objects of smell, taste and hearing exist in the shadows compared to solid materials. He concludes that sound has a different ontology and materialism:
"...a conception of being and matter that can account for objecthood better than an ontology of objects can account for sounds." (Cox, 2013).

According to Cox (2009), sound instead affirms an ontology of flux, where objects are replaced by events; a sonic philosophy of sound as flux, event and effect.

The same can be stated about computational material. It too can be described as an intangible matter and as an ontology of flux. We are bodily affected through, with, and by computational material, and no longer differentiate between the subjective inside and technology from the outside. Rather than dividing the human-technology relation into a matter of a foreground and a background we can unpack Hayles' (2012) claim that digital media and the actions of computers are embodied, that technical objects have agency or the potentiality of computational material as autonomous.

When Hayles expanded the concept of technogenesis, the idea that humans and technics coevolve, the focus was on contemporary digital technologies. She relates technical beings versus embodied living beings and focused on the interfaces between programmable machines and humans:

\begin{abstract}
"...the actions of computers are also embodied, although in a very different manner than with humans. The more one works with digital technologies, the more one comes to appreciate the capacity of networked and programmable machines to carry out sophisticated cognitive tasks, and the more the keyboard comes to seem an extension of one's thoughts rather than an external device on which one types." (Hayles, 2012, p. 3).
\end{abstract}

Thus, embodiment takes the form of an extended cognition where larger networks beyond the desktop computer are entangled with human agency and thought. Hayles clearly described technical objects as having agency. In the sense that technical objects are agents of complex temporalities, in evolutionary terms, they are repositories of change. (Hayles, 2012, p. 85)

Carvalhais (2010) addresses the autonomous quality of programmable media beyond their creators and users:

\footnotetext{
"A system's autonomy can be regarded not only as an amount of control that is conferred to or appropriated by it but also as a transfer of some amount of agency to the system." (Carvalhais 2010, p. 421).
}

He compares procedural systems to biological systems and claims that computational material too can be complex. With reference to Herbert A. Simon he describes an inner and outer environment of a system as the substance and organization of the 
artefact and the operating surroundings (Carvalhais, 2010, p. 634). Manovich (2001) makes a related distinction between the cultural layer and the computational layer as the distinction between the interface and what the computer reads.

Computational material is potentially autonomous. Computational media and sound are not just mediators, but also programmable, and thus potentially autonomous beyond their makers and users/listeners. The notion of sound as material and computational material is interesting in relation to the rowdy krause. Is the rowdy krause autonomous, and who is the author of the voice of the new species? What is the role of the computational material in relation to the rowdy krause? In what follows, we situate potentially autonomous technological forms as material forces within ecosystems and ask how an example such as the rowdy krause impacts and is impacted by the relationality of sound within its environment.

\section{ECO-TECHNOGENESIS}

Eco-technogenesis describes the co-becoming of ecosystems and technologies. Hayles asserts,

"technical objects embody complex temporalities enfolding past into present, present into future" (2012, p 86)

While Hayles applies this idea to human development, here we apply it to an understanding of the past and future development of ecosystems. The contemporary farm is a good working example of eco-technogenesis (Mazoyer, 2006). The typical large wheat monoculture found in mid-western North America, for example, did not arise overnight, but is the result of tens of thousands of years of coevolutionary development involving technical ensembles, human societies, and ecosystems. When the first hunter-gatherers scattered seeds from their food in a known location or the first metalworkers forged a plow, their goal was not to produce unbroken hectares of wheat monoculture. And yet, that ecosystem is only possible because of the advent of seed harvesting and metal plows, the selection and evolution of new crops and countless other technological and biological changes.

Examples of the co-evolution of humans, technology, and ecosystems abound, but what about non-human eco-technogenesis? This is a more difficult proposition to consider, given the difficulty of observing the slow changes continually modified by feedback loops between animals and environments occurring on evolutionary and geological timescales. Scholars have pointed to habitat-modifying species like the beaver as an example. Beavers are best known for cutting trees to dam rivers, creating larger pools of water within a river ecosystem. The technical object of the dam is, on its own, a significant factor in the formation of these dammed river ecosystems. It has an impact on the plant and animal communities in the ecosystem (Rybczynski, 2007), reshaping the network of interactions and relationships in the landscape. Dams become an essential component of the development of the ecosystem. Considering the evolutionary history of beavers provides evidence that this behaviour evolved through technological and evolutionary reinforcement. Natalia Rybczynski argues the building of dams evolved from simpler behaviours like cutting and feeding on smaller vegetation (Ibid., 2007). It implies a long, slow, multigenerational process in which dams began as smaller debris and eventually took the form of larger constructions, thereby reconstituting the ecosystem and reinforcing the behaviour. Beavers' activities are implicated in the evolution of fish and amphibians in dammed rivers as well as the defences of nearby tree species (Ibid., 2007). Beaver dams can be considered a canonical example of eco-technogenesis.

\subsection{Sound and eco-technogenesis}

Returning to soundscape ecology, we argue sound provides a domain in which to think through the possibility of eco-technogenesis. In fact, this idea is not entirely new. The intermeshing of sound, technology, and ecology exploded into public consciousness in 1962 with the publication of Carson's landmark book Silent Spring, in which she revealed the devastating effects of industrial chemicals on bird populations by pointing to gaps in the sound spectrum as bird species went extinct. Carson's method of measuring ecological health using sound predated yet paved the way for the acoustic niche hypothesis (ANH) (Krause, 1987) and the acoustic adaptation hypothesis (AAH) (Morton, 1975). The ANH is based on empirical observations that suggest sounds produced by species vocalizing within an ecosystem tend not to interfere with one another, creating a partitioning of the acoustic range (Sueur and Farina, 2015, 495). Relatedly, the AAH argues animal-generated sounds have adapted to their particular habitat, taking into account the properties of the landscape and plant life to maximize sound dispersal (Sueur and Farina, 2015, 495). The ANH and AAH provide the basis for thinking in terms of the co-constitution of sound and landscape. Based on Carson's and Krause's work, an ecosystem's soundscape became an indicator of its diversity and health. Loss of diversity across the acoustical space indicated an imbalance and an infiltration of human activity in the ecosystem. For example, Krause observed that smaller parks in the American Northwest established by lumber companies and characterized by a monoculture of young pines displayed a shocking lack of biodiversity evidenced by large gaps in the acoustical space (Krause, 1993). 
Soundscape ecology allowed for thinking of the intermeshing of sound, technology, and ecology and the technogenesis of soundscapes, while preserving the nature/culture divide. Having defined ecotechnogenesis, we now focus on the possibility of technogenesis across human, non-human, and nonorganic or technological systems. Throughout the course at Catch, we considered autonomous agents capable of creative sound generation through case studies and in practice. Our aim here is to situate generative sound practices within local ecologies. Kadish's rowdy krause, developed over the course of his doctoral studies and presented for the first time at Catch, provides a case study. Given that we have accepted sound as a material force in an ecosystem, we conclude by speculating on the ethics of an eco-technogenesis that includes nonorganic sound generation.

There are a number of automated or robotic soundgenerating systems that are designed specifically to engage with ecosystems in a dynamic and generative manner. David Dunn's Sonic Mirror (1986) is an early example of this type of work. Dunn's Sonic Mirror, which he considers a sound performance, arose from an interest in rules and systems for processing and reproducing soundscapes (Dunn, 2013). Sonic M irror involves the recording of sound in an ecosystem by an autonomous computer system, the processing and modulation of that recording, and the subsequent reprojection of the sound into the ecosystem. Dunn, who was trained as a composer, observed that the ecosystem inhabitants began to engage with the recording and playback system, and noted the ecosystemic nature of sound:

\footnotetext{
"The song of a bird is not just grist for compositional manipulation; it is a code of signification not only between members of that particular species, but also for the extended fabric of mind that forms the biohabitat within which that species resides" (Dunn, 2013, p. 100).
}

Dunn's statement parallels our own argument, that eco-technogenesis demands that non-organic selforganizing systems be considered as relational elements within an ecosystem.

In 2001, biologist Claus Emmeche specualted, "Does a robot have an Umwelt?" (Emmeche, 2001). The biologist Jakob von Uexküll's concept of Umwelt is defined as an organism's perceptual world (1909, 1992). From the concept of Umwelt, it follows that an organism acting within a perceptual environment relies on signs to interpret the material world and is a communicative being, even if one does not accept this as proof of high-level reasoning. Emmeche speculated autonomy and self-organization would be necessary qualities for occupying an Umwelt, and that robots could therefore have an Umwelt. In response, biologist Winfried Nöth offered the example of a robot successfully moving around its environment and argued even if it did have an experience of Umwelt, it would be impossible for humans to know anything about that experience (Nöth, 2001). In 2012, Hayles referring to Uexküll's famous example of a tick (Uexküll, 1992) agreed, arguing if an animal as simple as a tick could have an Umwelt, surely a spatially-aware robot could. (Hayles, 2012, p. 249n4). Each of these examples stresses vision and proprioception as markers of semiosis. We argue here just as a robot moving around its environment has an Umwelt, an artificial intelligence system occupying an acoustical niche has an Umwelt.

The rowdy krause meets this threshold by listening to its environment, identifying the least utilized portions of the audio spectrum, and evolving a voice to fill those frequencies. It performs the acoustic niche hypothesis as an autonomous technological species, its Umwelt framed by its primary sensory organ: its microphone. As its vocalizations evolve to fill previously empty portions of the soundscape, how do existing inhabitants of the ecosystem perceive its calls? Its interference in their own communication is minimal by design, but the rowdy krause's calls are nevertheless part of the acoustic environment.

\subsection{Biosemiotics as a basis for an ethics of generated sound in eco-technogenesis}

Technogenesis belies the idea of infiltration and instead presents the problem of intermeshing and relationality. Relationality forces the question of ethics, a code that governs behaviour within a social setting. Hoffmeyer, Kull, Tønnensen, Beever, and Hendlin have all approached ethics from the perspective of biosemiotics, the production and interpretation of signs in the living world beyond human language. (Hoffmeyer, 1993; Kull, 2001; Tønnensen, Beever and Hendlin, 2015). We argue here that the creative use of sound requires an exploration of the ethics of sound generation within an ecosystem, an occurrence that only promises to increase as techniques for sonic manipulation continue to develop. By thinking through ecotechnogenesis, sounds regardless of origin contribute for better or worse to a biosemiotic ecosystem, an environment within which the generation and interpretation of sounds as signs evolve in co-constitution with one another regardless of origin, whether biological, natural, or technological. Given this description, preserving the nature/culture divide proves likely to be a fruitless enterprise in the face of ongoing technological development. As sound-generating autonomous agents increasingly become part of the soundscape, it is crucial we consider how to design responsible inhabitants. This idea follows Cox's argument that sound art provides an opportunity to explore the ontogeny of sound (Cox, 2009). But whereas in Cox's argument, sound art points to a realm of 
sound outside human sensory experience, in our estimation, sound not only points to a realm of sensory experience outside the human, it acts as a source of potential various meanings to an ecosystem's inhabitants. Even if these sounds are generated by non-living self-organizing systems, their potential to occupy an Umwelt makes them "morally considerable" (Beever and Tønnessen, 2015, p. 45).

Part of the appeal but also the challenge of biosemiotic ethics is its insistence on the existence of systems of meaning that reside outside of human experience (Hoffmeyer, 1993; Kull, 2001; Tønnensen, Beever and Hendlin, 2015). Traditionally, however, conservationist rhetoric has relied on anthropocentric notions of beauty to drive home the necessity of caring for ecosystems (Harries-Jones, 2008). Like beautiful works of art in a museum, it was reasoned, landscapes should be preserved for future generations to enjoy. Even Carson relied on this line of thinking by lamenting the loss of bird songs for human ears (Carson, 1962). Recently, it has become apparent that these humancentred values are not only questionable in their efficacy, but also potentially harmful to the ecosystems they try to protect (Harries-Jones, 2008). In emphasising stasis over dynamics, the idea of beauty as applied to ecosystems betrays their essence. Peter Harries-Jones argued Bateson's idea of an ecological aesthetics, which leaves behind human-centred ideas of beauty, has finally started to gain traction, if without full appreciation for its biosemiotic implications (Ibid.). Bateson's concept of ecological aesthetics, in which systems interact through feedback, provides a foundation for thinking of ecosystems as composed of layers that add up to something greater than themselves (1972). In other words, ecological aesthetics is a type of holistic thinking that resists reductionism.

\section{CONCLUSION}

Throughout this article, we considered sound generated by an autonomous agent as contributing to the co-constituted becoming of ecosystems and technologies. Based on our collaborative work and discussions, we offer insights into sound as computational material, eco-technogenesis, and the possibility for an ethics of sound generation based on biosemiotics in this new ecological paradigm.

We do not present an exhaustive account of the subjects but invite other scholars and practitioners to continue the conversation and further explore the subject of technogenesis in relation to sound and ecosystems. Finally, the thorny questions of ethical approaches to eco-technogenesis will continue to present themselves in the future, especially as the possibilities for technological sound generation increase. Here we offer a starting point for considering ethical relationality from the perspective of biosemiotics.

\section{Acknowledgments}

Artistic and Curatorial Practices in the Age of Technogenesis was a joint project between Catch, the IT-University of Copenhagen and Aalborg University. Thank you to the academic supervisors Morten Søndergaard Laura Beloff and Catch supervisor Majken Overgaard. Megan Hines would like to thank the Stony Brook University Graduate Student Organization for their financial support.

\section{REFERENCES}

Bateson, G. (1972) Steps to an Ecology of Mind. Ballantine, New York.

Beever, J. and Tønnessen, M. (2015) 'Justifying Moral Standing by Biosemiotic Particularism', Zeitschrift für Semiotik 37 (3-4), pp. 31-53.

Carson, R. (1962) Silent Spring. Houghton Mifflin, Boston.

Carvalhais, M. (2010). "Towards a Model for Artificial Aesthetics. Contributions to the Study of Creative Practices in Procedural and Computational Systems." Doctoral thesis. Universidade do Porto.

Chattopadhyay, B. (2017). 'Beyond Matter: Objectdisoriented Sound Art', Seismograph. $<$ https://seismograf.org/fokus/sound-artmatters/beyond-matter-object-disoriented-soundart> (retrieved 09 November 2019).

Cox, C. (2009) 'Sound Art and the Sonic Unconscious', Organised Sound 14 (1), pp. 1926.

Cox, C. (2013). 'Sonic Philosophy', ARTPULSE Magazine. <http://artpulsemagazine.com/sonicphilosophy> (retrieved 09 November 2019).

Dunn, D. (2013) 'Nature, Sound Art, and the Sacred', in David Rothenberg (ed.), The Book of Music and Nature: A n A nthology of S ounds, Words, $T$ houghts. Wesleyan University Press, Wesleyan.

Emmeche, C. (2001) 'Does a robot have an Umwelt?', Semiotica 134 (1/4), pp. 653-693.

Harries-Jones, P. (2008) 'Gregory Bateson's 'Uncovery' of Ecological Aesthetics', in Hoffmeyer, J. (ed.), A Legacy for Living Systems: Gregory $B$ ateson a $S P$ recursor to $B$ iosemiotics. Springer, Dordrecht.

Hayles, N. K. (2012) How We Think: Digital Media and Contemporary Technogenesis. University of Chicago Press, Chicago. 
Hoffmeyer, J. (1993) 'Biosemiotics and ethics.' in Witoszek, N. and Gulbrandsen, E. (eds.), Culture and E nvironment: I nterdisciplinary A pproaches. Centre for Development and the Environment, Oslo.

Klett, J. (2014) 'Sound on Sound: Situating Interaction in Sonic Object Settings', Sociological Theory 32 (2), pp. 147--161.

Krause, B. L. (1987) 'Bioacoustics, Habitat Ambience in Ecological Balance', Whole $E$ arth Review 57, pp. 14-18.

Krause, B. L. (1993) 'The Niche Hypothesis: A hidden symphony of animal sounds, the origins of musical expression and the health of habitats,' The Explorers Journal, (Winter), pp. 156-160.

Kull, K. (2001) 'Biosemiotics and the problem of intrinsic value of nature', Sign Systems Studies 29, 1: pp. 353-365.

Labelle, B. (2006). Background Noise: Perspectives on Sound Art. Continuum, London.

Manovich, L. (2001) The Language of New Media. MIT Press, London.

Margulis, L. (1970) Origin of eukaryotic cells; evidence and research implications for a theory of the origin and evolution of microbial, plant, and animal $c$ ells on $t$ he $P$ recambrian ea rth. New Haven: Yale University Press.

Mazoyer, M., \& Roudart, L. (2006). A H istory of World Agriculture: From the Neolithic Age to the Current Crisis. Earthscan, London.

Morton, E. S. (1975) 'Ecological Sources of Selection on Avian Sounds', The American Naturalist, 109(965), pp. 17-34.

\footnotetext{
${ }^{1}$ Thapen, N. https://dood.al/pinktrombone/

(retrieved 09 November 2019).
}

Nöth, W. (2001) 'Semiosis and the Umwelt of a robot', Semiotica 134 (1/4), pp. 695-699.

Rybczynski, N. (2007) 'Castorid Phylogenetics: Implications for the Evolution of Swimming and Tree-Exploitation in Beavers', Journal of Mammalian Evolution 14(1), pp. 1-35.

Schaeffer, P. (1966) Traité des objets musicaux. Éditions du Seuil, Paris.

Schaffer, R. M. (1969) The New Soundscape. Berandol Music Limited, Ontario.

Søndergaard, M. (2019) 'Exscribing the Archive: Curating the Unheard (in Scandinavia)'. in Weibel, P. (ed.) Sound A rt. MIT Press, Cambridge.

Stanley, K. O. and Miikkulainen, R. (2002) 'Evolving Neural Networks through Augmenting Topologies', Evolutionary Computation, 10(2), pp. 99-127.

Stiegler, B. (1998). Technics and Time 1. Stanford University Press, Stanford.

Sueur, J. and Farina, A. (2015) 'Ecoacoustics: the Ecological Investigation and Interpretation of Environmental Sound', Biosemiotics 8, pp. 493-502.

Tønnessen, M., Beever, J. and Hendlin, Y. (2015) "Introducing Biosemiotic Ethics', Zeitschrift $f$ ür Semiotik 37 (3-4), pp. 3-12.

Uexküll, J. (1909) Umwelt und Innenwelt der Tiere. Julius Springer, Berlin.

Uexküll, J. (1992). 'A Stroll Through the Worlds of Animal and Men' in Uexküll, T. (ed.) Semiotica 89 (4), pp. 273-391. 